A Si-micromachined 48-stage Knudsen pump for on-chip vacuum

This article has been downloaded from IOPscience. Please scroll down to see the full text article.

2012 J. Micromech. Microeng. 22105026

(http://iopscience.iop.org/0960-1317/22/10/105026)

View the table of contents for this issue, or go to the journal homepage for more

Download details:

IP Address: 141.211.173.82

The article was downloaded on 25/06/2013 at 20:34

Please note that terms and conditions apply. 


\title{
A Si-micromachined 48-stage Knudsen pump for on-chip vacuum
}

\author{
Naveen K Gupta ${ }^{1}$, Seungdo An and Yogesh B Gianchandani \\ Department of Electrical Engineering and Computer Science, University of Michigan, \\ 1301 Beal Avenue, Ann Arbor, MI 48109, USA \\ E-mail: gnaveen@umich.edu,sdan@umich.edu and yogesh@umich.edu
}

Received 19 May 2012, in final form 6 July 2012

Published 3 September 2012

Online at stacks.iop.org/JMM/22/105026

\begin{abstract}
This paper describes a thermal transpiration-driven multistage Knudsen pump for vacuum pumping applications. This type of pump relies upon the motion of gas molecules from the cold end to the hot end of a channel in which the flow is restricted to the free molecular or transitional regimes. To achieve a high compression ratio, 48 stages are cascaded in series in a single chip. A five-mask, single silicon wafer process is used for monolithic integration of the designed Knudsen pump. The pump has several monolithically integrated Pirani gauges to experimentally measure the vacuum pumping characteristics of the pump. It has a footprint of $10.35 \times 11.45 \mathrm{~mm}^{2}$. For an input power of $1350 \mathrm{~mW}$, the fabricated pump self-evacuates the encapsulated cavities from 760 to $\approx 50$ Torr, resulting in a compression ratio of 15 . It also pumps down from 250 to $\approx 5$ Torr, resulting in a compression ratio of 50 . Each integrated Pirani gauge requires $\approx 3.9 \mathrm{~mW}$ of power consumption, and its response is sufficiently sensitive in the operating pressure range of 760-1 Torr.
\end{abstract}

(Some figures may appear in colour only in the online journal)

\section{Introduction}

Micropumps targeted at a wide range of applications have been reported in the literature [1-10]. Most research efforts have been directed at motion-based pumping mechanisms $[4,6,8,10]$, which are prevalent in macroscale pumping instruments. These include, for example, peristaltic and rotary pumps. However, moving parts present challenges at the microscale as the surface area to volume ratio of the components increases. To achieve large compression ratios, it is necessary to build structures that provide relatively large displacement at relatively high frequencies; these are not easily integrated on a microchip. In addition, high frictional losses can compromise operational life. This effort focuses on the Knudsen pump, a motionless, thermomolecular pump, which does not have any moving parts [11]. Such micropumps are potentially useful for cavity pressure modulation and highprecision on-chip microfluidic applications, and have also been explored for gas chromatography [12].

\footnotetext{
${ }^{1}$ Author to whom any correspondence should be addressed.
}

The mechanism for Knudsen pumps is the phenomenon of thermal transpiration $[11,13,14]$, which results in the movement of gas molecules from the cold end to the hot end of a narrow channel subjected to a longitudinal temperature gradient [15-18]. A narrow channel, in this case, has hydraulic diameter smaller than or comparable to the mean free path of the gas molecules. This is essentially a surface phenomenon and hence the increase in the surface area to volume ratio of the device with miniaturization favorably affects the performance of the pump.

Although the first functional Knudsen pump was demonstrated by Knudsen himself in 1909 [11], the challenge of fabricating sufficiently narrow channels for operation without a backing pump has limited its widespread adoption. With advancements in the microfabrication techniques, this technology has received more attention [19-27]. The past two decades have seen several efforts demonstrating the use of bulk micro- or nanoporous materials for thermal transpirationdriven Knudsen pumping [28-37]. However, achieving high thermal isolation and generating high pressure heads using this approach remain a challenge. 
For these pumps to achieve high compression ratios, one major challenge is that it is necessary to pack a large number of stages (operating in series) into a small footprint. Micromachining technologies are suitable for integrating these stages in a small area using lithography-based batch fabrication processes. While mesoscale (multistage) Knudsen pumps have demonstrated compression ratios of $\approx 1.2[37,38]$, the first fully micromachined on-chip single-stage Knudsen pump, reported in 2005 , achieved a compression ratio of $\approx 2$ [22]. This single-stage micromachined Knudsen pump used a sixmask, two-wafer process.

This paper reports on a 48-stage micromachined Knudsen pump with integrated Pirani gauges, using a five-mask, singlewafer structure ${ }^{2}$. Using a serially cascaded multistage design, this pump achieves substantially higher compression ratios. A pressure drop in excess of 700 Torr is achieved in an air ambient at atmospheric pressure. The pump is operational over a range of ambient pressure starting from atmospheric pressure to less than 10 Torr. The principle of operation of the Knudsen pump is described in section 2 . The design analysis for the device has been presented in section 3 . The details of the device fabrication process and results are discussed in sections 4 and 5 , followed by a discussion of experimental results in section 6 .

\section{Principle of operation}

If two sealed chambers, at equal pressures, are connected by a narrow channel that supports free molecular or transitional flow, a thermal gradient results in flow from the cold end to the hot end of the narrow channel. In steady state, the ratio of pressures in the two chambers is (ideally) given by

$$
\frac{P_{\mathrm{H}}}{P_{\mathrm{C}}}=\left(\frac{T_{\mathrm{H}}}{T_{\mathrm{C}}}\right)^{\frac{1}{2}}
$$

where $P_{\mathrm{H}}$ and $P_{\mathrm{C}}$ are pressures, and $T_{\mathrm{H}}$ and $T_{\mathrm{C}}$ are temperatures at the hot end and at the cold end of the narrow channel, respectively. This phenomenon of thermal transpiration is exploited by Knudsen pumps [11, 22]. If two single-stage Knudsen pumps are connected in series such that the hot chamber of one stage is connected to the cold chamber of the second stage via a wide channel that supports gas flow in the viscous regime, the pressure changes progressively across the narrow channels in the two stages (figure 1). Thus, several Knudsen pumping stages can be cascaded in series to achieve high vacuum. A multistage approach is useful in achieving a large pressure differential while limiting the temperature bias required across individual stages. The (ideal) pressure ratio with $n$ stages is provided by

$$
\frac{P_{\mathrm{hi}}}{P_{\text {low }}}=\left(\frac{T_{\mathrm{H}}}{T_{\mathrm{C}}}\right)^{\frac{n}{2}},
$$

where $P_{\text {hi }}$ is the pressure at the high-pressure end of the multistage Knudsen pump and $P_{\text {low }}$ is pressure at the lowpressure end of the Knudsen pump. This assumes the condition when the gas in the narrow channel is in the free molecular regime and hence gas molecule-wall interactions are dominant over molecule-molecule interactions.

2 Portions of this work have been published in conference abstract form in [39].

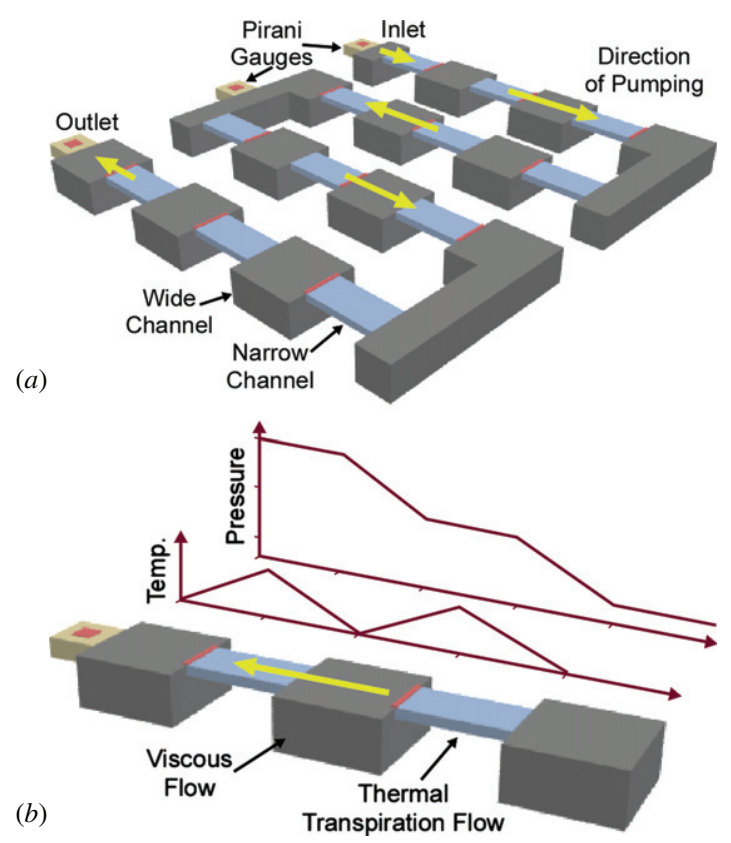

Figure 1. (a) Schematic of a multistage Knudsen pump. The hot end of one stage is connected to the cold end of the next stage via a wide channel. Pirani gauges are used to measure the pressure. (b) Close-up view of two of the stages operating in series. The narrow channels support thermal transpiration-driven Knudsen pumping, whereas the wide channels support viscous flow. Thermal transpiration-driven flow causes a pressure rise (or drop) in the narrow channels, and viscous flow in the wide channels helps retain the pressure rise (or drop). Hence, the pressure heads across each of the stages add up, without the need to increase the operating temperature of each of the stages.

More accurate analyses of thermal transpiration flow are provided in [40, 41]. These analyses suggest that the mass flow rate along a narrow rectangular channel subjected to a longitudinal temperature gradient is [41]

$$
\dot{M}=\left(\frac{Q_{\mathrm{T}} \Delta T}{T_{\mathrm{avg}}}-\frac{Q_{\mathrm{P}} \Delta P}{P_{\mathrm{avg}}}\right) \frac{a^{2} b P_{\mathrm{avg}}}{l} \sqrt{\frac{m}{2 k_{\mathrm{B}} T_{\mathrm{avg}}}},
$$

where $l$ is the length of the narrow channel, $a$ is the height of the channel, $b$ is the width of the channel, $k_{\mathrm{B}}$ is the Boltzmann constant, $m$ is the mass of the gas molecule being pumped, and $Q_{\mathrm{T}}$ and $Q_{\mathrm{P}}$ are the numerically evaluated thermal creep flow and pressure-driven flow coefficients. The coefficients are listed in [41]. In this model, the forward gas flow is described by $Q_{\mathrm{T}}$, whereas the opposing viscous return flow is described by $Q_{\mathrm{P}}$. The temperature and pressure variables are defined as

$$
\begin{gathered}
\Delta T=T_{\mathrm{H}}-T_{\mathrm{C}}, \\
\Delta P=P_{\mathrm{H}}-P_{\mathrm{C}}, \\
T_{\mathrm{avg}}=\left(T_{\mathrm{H}}+T_{\mathrm{C}}\right) / 2, \\
P_{\mathrm{avg}}=\left(P_{\mathrm{H}}+P_{\mathrm{C}}\right) / 2 .
\end{gathered}
$$

In the absence of gas flow, the equilibrium pressure gradient, in which the thermal creep flow and pressure-driven flow are nullified by each other, is provided by

$$
\frac{\mathrm{d} P}{\mathrm{~d} x}=\frac{Q_{\mathrm{T}}}{Q_{\mathrm{P}}} \frac{P}{T} \frac{\mathrm{d} T}{\mathrm{~d} x} .
$$




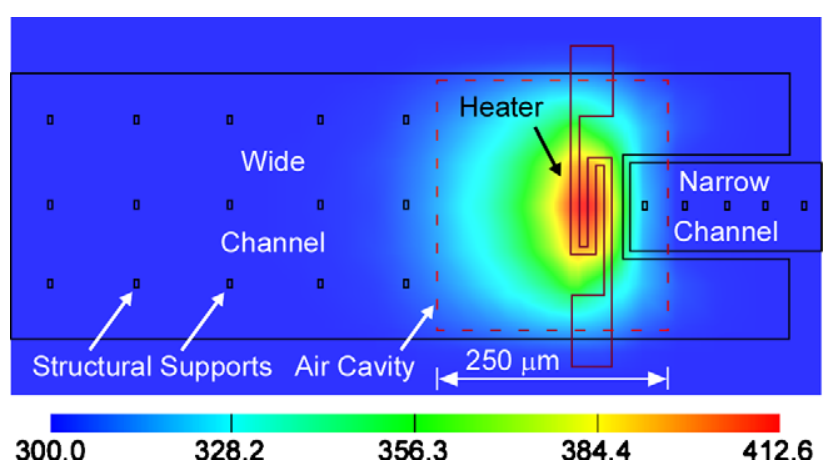

Figure 2. Modeled distribution of temperature on the top surface of the Knudsen pump for a given input power of $28.1 \mathrm{~mW}$ per stage. The Knudsen pump is designed to limit the maximum operating temperature to $<450 \mathrm{~K}$.

The flow coefficients, $Q_{\mathrm{P}}$ and $Q_{\mathrm{T}}$, depend on the rarefaction parameter defined as

$$
\delta_{\mathrm{avg}}=\frac{\sqrt{\pi}}{2 K n}=\frac{\sqrt{\pi}}{2} \frac{d}{\lambda},
$$

where $K n$ is the Knudsen number, which is given by the ratio of the mean free path of the gas molecules, $\lambda$, to the hydraulic diameter of the channel, $d$. Mathematically, for a narrow channel, $K n>1$. In contrast, for $K n \ll 1$, the gas flow in the channel is in the viscous regime. The pressure gradientdriven viscous flow through a channel is given by Poiseuille's equation

$$
Q_{\mathrm{POS}}=\frac{\pi d^{4}}{128 \mu l} \Delta P,
$$

where $d$ is the hydraulic diameter of the channel, which allows gas flow in the viscous flow regime. $\Delta P$ is the pressure head across the channel, $l$ is the length of the channel and $\mu$ is the dynamic viscosity of the gas.

\section{Design analysis}

A 48-stage Knudsen pump with monolithically integrated Pirani gauges is designed for the purpose of this study. Sacrificial polysilicon is used to define narrow channels. Bulk silicon cavities are used to define wide channels. Thinfilm silicon dioxide/silicon nitride is used to encapsulate the wide and narrow channels.

Finite element analysis (FEA) is used to investigate the thermal behavior of the device. Figure 2 shows the modeled thermal response of each of the stages of the Knudsen pump for an ambient temperature of $300 \mathrm{~K}$. A $110 \mathrm{~K}$ rise in the heater temperature is expected for an input power of $28.1 \mathrm{~mW}$. The thermal map suggests that the temperature gradient is steepest along the narrow channel, indicating that the primary heat loss is along the narrow channel. This temperature gradient is the driving force for gas pumping from the cold end to the hot end. Since the hot end of the narrow channel has about half of the temperature rise of the heater (figure 2), $355 \mathrm{~K}$ is used as $T_{\mathrm{H}}$ in the following performance estimation. The wide channel from the heater to the cold end of the next narrow channel restores the temperature from $T_{\mathrm{H}}$ to $T_{\mathrm{C}}$ with negligible change in pressure. The gas flow in this channel is in the viscous regime.

The Sharipov model [41] is used to estimate the pressure ratio generated across each of the stages based on the simulated thermal distribution of the device, using equations (3)-(9). According to the Sharipov model, for a Knudsen pump with $30 \mu \mathrm{m}$ height of the wide channel and $0.15 \mu \mathrm{m}$ height of the narrow channel with the hot end at $355 \mathrm{~K}$ and the cold end at $300 \mathrm{~K}, 48$ stages are expected to pump down from 760 to 97 Torr. Using the same number of stages, the pressure can also be reduced from an ambient pressure of 250 to 18 Torr. The mean free path of the air molecules at 18 Torr is about $3 \mu \mathrm{m}$ at $350 \mathrm{~K}$. Hence, for the reduction of pressure to about 18 Torr, the wide channels are required to have hydraulic diameters significantly larger than $3 \mu \mathrm{m}$ to limit the backflow at low operating pressures.

The operating pressure levels are used to estimate the separation between adjacent structural supports for the diaphragms over the wide and the narrow channels. These structural supports (figure 2) are required to limit the deflection of the diaphragms during the Knudsen pump operation, which would otherwise obstruct the gas flow. A finite element model is used to estimate the separation of the structural supports for the diaphragms over the polysilicon channels. The device can accommodate a 760 Torr ambient pressure level. Under these operating conditions, the worst-case deflection of the diaphragm is expected to occur at the 48th stage (i.e. the pump inlet). The pressure above the diaphragm is 760 Torr and the pressure under the diaphragm, in the wide and the narrow channels, is set to $\approx 0$ Torr for simulation of the maximum deflection. For these operating conditions, the structural supports in the narrow channel are located at $50 \mu \mathrm{m}$ spacing, limiting the deflection of diaphragm to $<7 \mathrm{~nm}$. Similarly, the structural supports in the wide channel are located at every $125 \mu \mathrm{m}$, limiting the deflection of diaphragm to $<0.1 \mu \mathrm{m}$.

For the purpose of this study, the Knudsen pumping stage located furthest downstream, i.e. at the pump outlet, is termed as the first stage of the 48-stage Knudsen pump. Similarly, the most upstream stage, i.e. at the pump inlet, is termed as the 48th stage. The Pirani gauges are identified by the stage number of the Knudsen pumping stage to which they are connected. For example, if a Pirani gauge is connected to the inlet of the 48th stage, it is named P48. Similarly, if a Pirani gauge is connected to the inlet of the first stage, it is named P1. The Pirani gauge connected to the outlet of the first stage is named P0.

The footprint for each of the stages of the Knudsen pump is $0.3 \times 1 \mathrm{~mm}^{2}$. The wide channel is $\approx 300 \mu \mathrm{m}$ wide and $\approx 750 \mu \mathrm{m}$ long, and the narrow channel is $\approx 100 \mu \mathrm{m}$ wide and $\approx 250 \mu \mathrm{m}$ long, whereas the cavity is $280 \mu \mathrm{m}$ wide and $250 \mu \mathrm{m}$ long. The footprint of the Pirani gauge is $250 \times 250 \mu \mathrm{m}^{2}$.

The 48 stages are laid out in a serpentine fashion with eight Knudsen pumping stages in a row. (Note that not all the intermediate stages have integrated Pirani gauges.) For the ease of testing, the heaters for all the Knudsen pumping stages are connected together so that they could be powered simultaneously using only two contact pads. The serpentine arrangement allows the heaters to be connected in eight parallel 


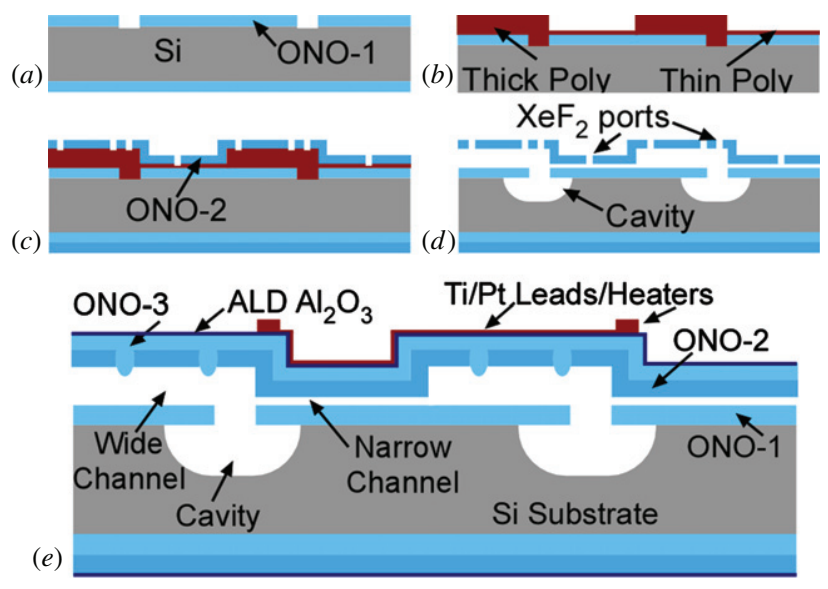

Figure 3. $(a)-(d)$ The series of steps involved in the fabrication of the 48-stage Knudsen pump with monolithically integrated Pirani gauges. (e) Sectional view of the final device drawn at a larger scale; narrow channels are required for thermal transpiration; wide channels are required to interconnect successive stages; cavities are used to increase the effective hydraulic diameter of the wide channel and for better thermal isolation of the heater and the leading edge of the narrow channel. This sectional view shows two consecutive stages. The top view of the single stage is shown in figure 2 .

branches with six heaters, connected in series, in each branch. The positive and the negative terminals of these eight branches are connected to two contact pads located at the top and the bottom of the chip.

\section{Fabrication process}

The fabrication process selected for the 48-stage Knudsen pump and the monolithically integrated Pirani gauges offers simplicity and high yield. Three important features are (1) thin (sacrificial) polysilicon is used to define narrow channels, (2) thick (sacrificial) polysilicon is used to define hydraulic interconnects between successive stages, and (3) a cavity is etched in bulk silicon to increase the hydraulic diameter of the viscous flow paths. The walls of the channels are fabricated by stress-compensated low-pressure chemical vapor deposited (LPCVD) oxide-nitride-oxide (ONO) layers.

The microfabrication process begins with deposition and patterning of the first ONO (ONO-1) layer, which is $1.25 \mu \mathrm{m}$ thick. The pattern defines openings, which are used for etching cavities in the bulk silicon (figure 3(a)). The ONO-1 film stress is $\approx 120 \mathrm{MPa}$. Sacrificial polysilicon of thickness $\approx 1.95 \mu \mathrm{m}$ is used for the wide channels and for the height of the air gap for the Pirani gauges [42] (figure 3(b)). A second sacrificial polysilicon layer, thickness $\approx 0.15 \mu \mathrm{m}$, is used to define the narrow channels (figure 3(b)). A second ONO (ONO-2) layer, thickness $1.17 \mu \mathrm{m}$, encapsulates the sacrificial polysilicon layers (figure $3(c)$ ). The ONO-2 film stress is $\approx 80 \mathrm{MPa}$. Structural supports (figure 2) for ONO-2 are defined at regular intervals by patterning rectangular pockets in the polysilicon layers. An array of slits, $1 \times 10 \mu \mathrm{m}^{2}$, is dry etched by deep reactive ion etching (DRIE) of the ONO-2 layer to define access ports for etching sacrificial polysilicon. The $\mathrm{XeF}_{2}$ gas is used to etch the thin/thick polysilicon and $30 \mu \mathrm{m}$ deep cavities in the bulk silicon (figure $3(d)$ ). The cavity is $\approx 30 \mu \mathrm{m}$ deep, and the $\mathrm{XeF}_{2}$ gas etches under the narrow channel by the same extent. Two layers of plasma-enhanced chemical vapor deposited (PECVD) ONO (ONO-3) with an intermediate nitride layer, total thickness of $3.12 \mu \mathrm{m}$, are used to block the $\mathrm{XeF}_{2}$ access ports in ONO-2 (figure 3(e)). The ONO-3 film stress is $\approx 25 \mathrm{MPa}$. An atomic layer deposited (ALD) $\mathrm{Al}_{2} \mathrm{O}_{3}$ layer, thickness $0.58 \mu \mathrm{m}$, is used to hermetically seal the pinholes in ONO-3. The $\mathrm{Al}_{2} \mathrm{O}_{3}$ film stress is $\approx 300 \mathrm{MPa}$. Finally, lift-off is used to define the Ti/Pt layer, total thickness $\approx 0.13 \mu \mathrm{m}$, for the heaters and the Pirani gauges. The same $\mathrm{Ti} / \mathrm{Pt}$ layer is used to define the electrical interconnects and contact pads. Figure 3(e) shows the sectional view of the final device. The diaphragm at the most downstream end is punctured to define the outlet for this 48-stage Knudsen pump, whereas the inlet is left sealed.

The use of ONO diaphragm instead of oxide-only diaphragm results in higher thermal conduction loss because the nitride has an order of magnitude higher thermal conductivity than oxide. However, stress compensation is critical to avoid unexpected curling/warping of the suspended structures. The ONO dielectric stacks are stress compensated to have mild tensile stress to avoid buckling of the suspended diaphragm due to compressive stress. The increase in parasitic heat loss due to the additional dielectric layers is compensated by increasing the thermal isolation of the heater from the silicon substrate.

Cavities are used to increase the hydraulic diameter of the (wide) channels, interconnecting successive Knudsen pumping stages depending on the desired operating pressure range of the Knudsen pump. The mean free path of the gas molecules is inversely proportional to the pressure. If the hydraulic diameter of the wide channels is not large enough, the wide channels will start supporting (reverse) thermal transpiration flow after attaining a certain vacuum level. The cavities also serve to thermally isolate the heating element for each of the Knudsen pumping stages. The heating elements for each of the stages are located on the diaphragm suspended over the cavity to minimize the parasitic heat loss into the substrate through the wide channel. The cavities are designed to undercut the narrow channel partially, such that the heated end of the narrow channel is suspended. This partially suspended architecture of the narrow channel is necessary to sustain high temperature gradient along the narrow channel. The high temperature gradient along the narrow channel translates into the high pressure gradient along the narrow channel.

Figure 4(a) shows the picture of the fabricated 48-stage Knudsen pump. It has a footprint of $10.35 \times 11.45 \mathrm{~mm}^{2}$. Figure 4(b) shows the close-up view of one of the diaphragms after ALD $\mathrm{Al}_{2} \mathrm{O}_{3}$ sealing but before the outlet of the Knudsen pump is opened. The optical fringing in the diaphragm symbolizes the hermetic sealing of the diaphragm under vacuum in the ALD tool. The fringing is because of the out-of-plane deflection of the diaphragm due to the vacuum created during ALD deposition of $\mathrm{Al}_{2} \mathrm{O}_{3}$. The structure retains the fringe pattern for several days, demonstrating that the diaphragm is perfectly sealed and allows no leakage of air. 


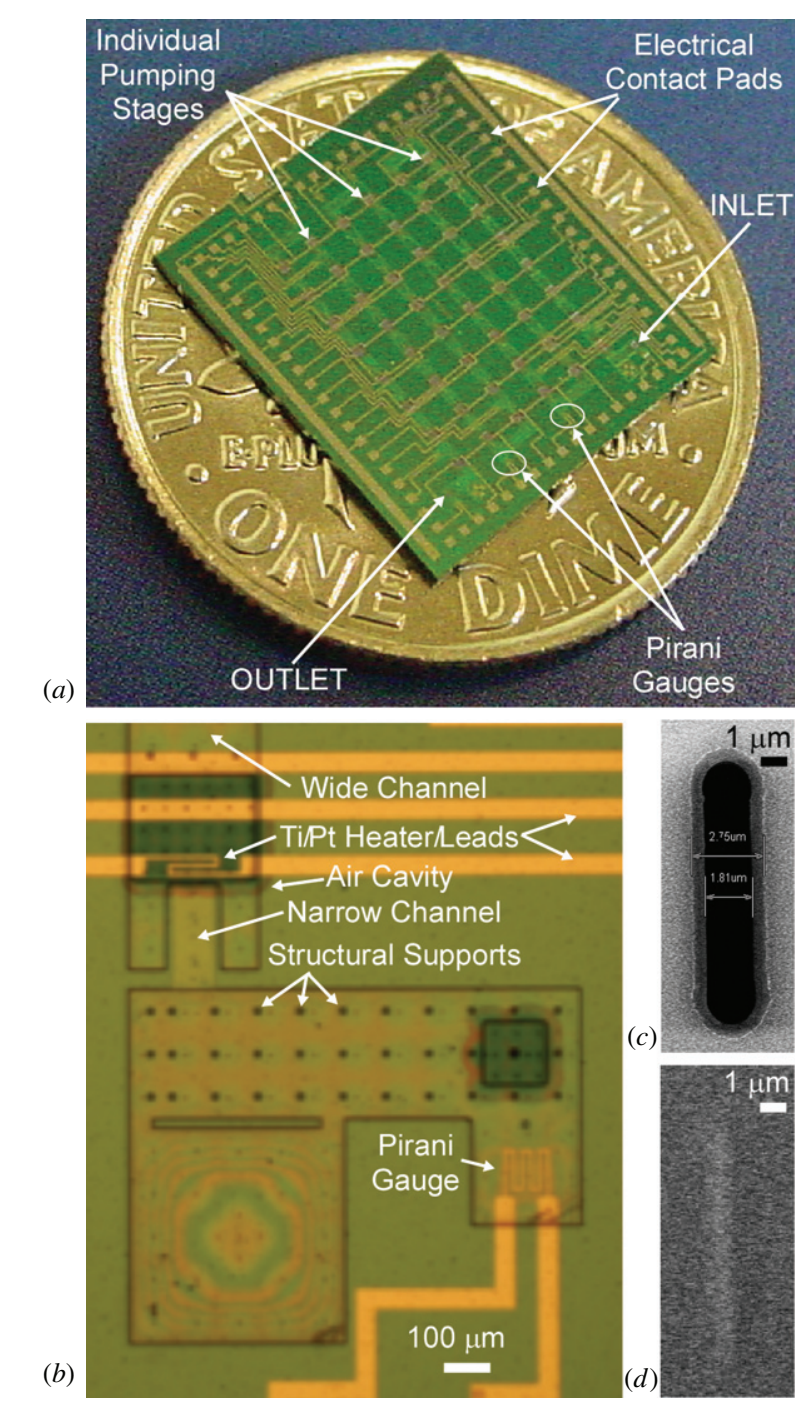

Figure 4. (a) Picture of the final fabricated device showing the individual Knudsen pumping stages, the inlet of the 48-stage pump, the outlet of the 48-stage pump, the Pirani gauges and the electrical contact pads. (b) Photograph of the device under a microscope just before the diaphragm at the outlet is punctured; optical fringing is observed due to the deflection of the diaphragm, which is sealed under vacuum; fringes disappear after the outlet is opened to the ambient. (c) SEM image of the $\mathrm{XeF}_{2}$ access port in the ONO-2 - used for the sacrificial etching of the polysilicon layers. (d) SEM image of the $\mathrm{XeF}_{2}$ access port in ONO-2 after sealing with PECVD ONO-3.

The fringe pattern disappears only after the outlet is opened intentionally. Figure $4(c)$ shows the SEM image of one of the $1 \times 10 \mu \mathrm{m}^{2}$ slits in the ONO-2 diaphragm for $\mathrm{XeF}_{2}$ gas etching of the sacrificial polysilicon layers. Figure $4(d)$ shows the SEM image of a slit, similar to that shown in figure 4(c), after the PECVD ONO-3 sealing step. Although the SEM image in figure $4(d)$ shows (visually) that the $\mathrm{XeF}_{2}$ access ports are sealed, acetone liquid seeps into the diaphragm during the lift-off process without the deposition of the $\mathrm{ALD} \mathrm{Al} \mathrm{O}_{2} \mathrm{O}_{3}$ layer. This suggests the presence of pinholes in ONO-3 even after the deposition of a $>3.8 \mu \mathrm{m}$ thick, seven-layered, ONO-3 dielectric stack. ALD $\mathrm{Al}_{2} \mathrm{O}_{3}$ is effective in sealing the pinholes in the ONO-3 layer.

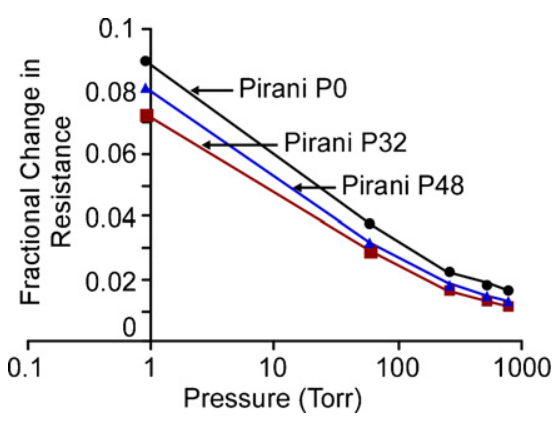

Figure 5. Response of the monolithically integrated Pirani gauges with the variation in pressure. Pirani P0 is connected to the outlet of the 1st stage, i.e. the outlet of the multistage Knudsen pump. Pirani P32 is connected to the inlet of the 32nd stage. And Pirani P48 is connected to the inlet of the 48th stage, i.e. the inlet of the multistage Knudsen pump.

\section{Experimental procedures and results}

The Knudsen micropump is mounted in an electronic package (Part\#: SQ1000-190-12GC by Sinclair Manufacturing Company, MA) for the purpose of testing. Silver grease (AIT Electro-grease ELGR8501) is used to enhance the thermal coupling between the chip and the electronic package. The thermal conductivity of the grease is $>8.6 \mathrm{~W} \mathrm{~m}^{-1} \mathrm{~K}^{-1}$. The heaters for the Knudsen pump, and Pirani gauges P0, P32 and P48 are wire-bonded to the electrical leads on the package.

The device is tested in a vacuum chamber, which is used to control the ambient operating pressure of the Knudsen micropump. Laboratory air ambient pressure is used for the testing. A commercial, pre-calibrated, pressure sensor (Adixen AHC-2010) is used to record and feedback control the pressure in the vacuum chamber. The vacuum chamber has several electrical feed-throughs, which are used to make electrical connections to the electronic package and hence to the device. These electrical feed-throughs are used to power the Knudsen pump and the Pirani gauges, and to record the signal from the Pirani gauges. Three Agilent 34401A multi-meters are used to read the output signal from the three Pirani gauges. These multi-meters are further connected to a computer operating a Labview $^{\mathrm{TM}}$ program through a National Instruments GPIBUSB-HS data transfer cable.

\section{Pirani gauge characterization}

The Knudsen pumping stages are maintained in off-state during the initial calibration of the Pirani gauges. The Pirani gauges of interest are connected in series, and a constant current of $5 \mathrm{~mA}$ is provided. The voltage drop across each Pirani gauge is recorded as a function of pressure in the test chamber. The resistance of each Pirani gauge is $\approx 155 \Omega$. The power consumption for each of these is $\approx 3.9 \mathrm{~mW}$ and varies in less than 10 percent with changes in pressure levels. Figure 5 shows the fractional change in the resistances of the Pirani gauges with pressure. The Pirani gauges are sufficiently sensitive to allow the detection of the pressure changes from 760 Torr down to sub-Torr levels. Using these calibration points, the measured pressures are obtained with linear interpolations between the neighboring points. 


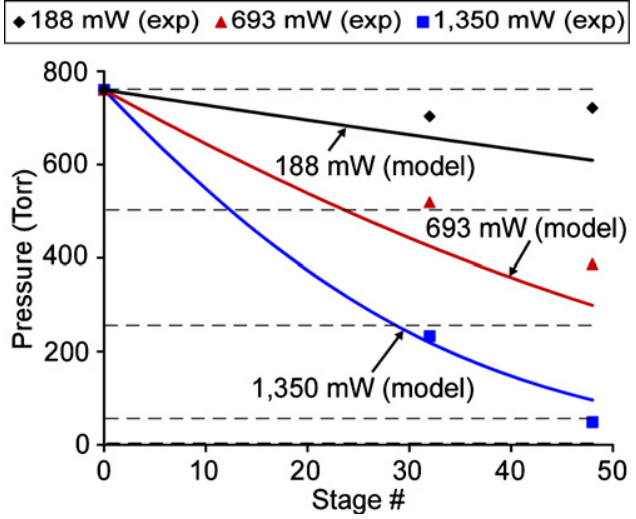

Figure 6. Variation in the experimentally measured and theoretically modeled pressures with stage number for different input powers. The pressures shown here are the pressures at the inlet of the respective stages. The pressure at the outlet of the Knudsen pump is the pressure at the outlet which is denoted by the 0th stage in this plot. The horizontal dotted lines are the Pirani calibration points which are used for linear interpolations for the pressure measurements.

Hence, the maximum error range in each measurement from linear interpolation is between the neighboring points in Pirani calibration.

\section{Knudsen pump operation}

The inlet of the Knudsen micropump is sealed and the outlet is opened to the 760 Torr ambient pressure. Figure 6 shows the variation in the pressure in different stages of the Knudsen pump for different input powers. For an input power of $1350 \mathrm{~mW}$, the pressure is reduced from 760 to $\approx 50$ Torr in experiment and to $\approx 98$ Torr in theory at its sealed inlet with air as the operating medium. In figure 6 , the isolated points represent the experimentally measured data, whereas the continuous line represents the theoretical estimate of the pressure in each of the stages.

The fabricated devices are also tested at the ambient pressures of 500 and 250 Torr to evaluate the performance that may be possible with the use of separate roughing pumps. Figure 7 shows the variation in the (steady-state) vacuum generated by the device, at its sealed inlet, with input power, for different ambient operating pressures. For an input power of $1350 \mathrm{~mW}$, the pump typically evacuates from 760 to $\approx 50$ Torr and from 250 to $\approx 5$ Torr. Hence, two such chips can be potentially integrated in series to design a Knudsen pump that can pump down from 760 to $<5$ Torr pressure levels.

\section{Discussion}

The plots comparing the models and measurements (figure 6) suggest that, for the stages that are more upstream, at 118 and $693 \mathrm{~mW}$, the experimentally measured pressure is higher than the idealized theoretical estimates. At $1350 \mathrm{~mW}$, the measured pressures show smaller deviations from the idealized theoretical estimates. One of the possible reasons for larger deviations at 118 and $693 \mathrm{~mW}$ could be smaller fractional changes in the resistance of the Pirani gauge at the high pressure range from 760 to 250 Torr (figure 5). This could

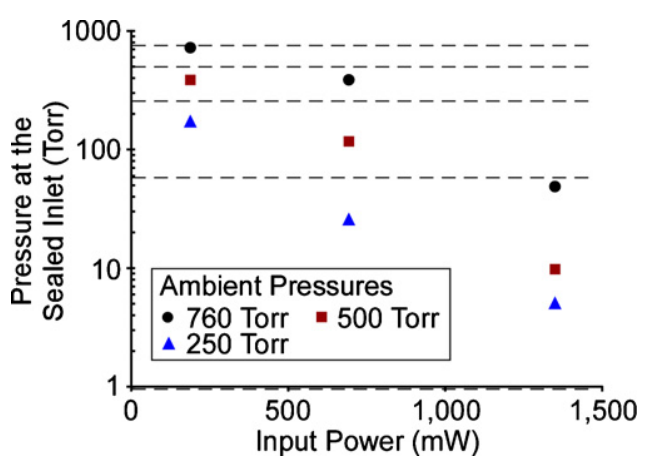

Figure 7. Variation in the pressure at the sealed inlet of the Knudsen pump with the input power for different ambient operating pressures. For an input power of $1350 \mathrm{~mW}$, the pump pumps down from 760 to $\approx 50$ Torr. For the same input power, while operating at an ambient pressure of 250 Torr, the pump evacuates the cavity at the upstream of the Knudsen pump down to $\approx 5$ Torr. The horizontal dotted lines are the Pirani calibration points which are used for linear interpolations for the pressure measurements.

result in larger errors in measurements at the high pressure range than those in measurements at the low pressure range, where the fractional changes in resistance are considerably larger. Another source of mismatch could be chip-to-chip and stage-to-stage variations of the suspended length of the narrow channel formed by $\mathrm{XeF}_{2}$ gas etching of the bulk silicon. These variations could result in errors in the temperature estimations of the hot end of the narrow channel at an applied power, because the hot end of the narrow channel is located at a half point from the heater to the thermal ground. The variation in the suspended length of the narrow channel in a wafer is approximately $\pm 20 \%$ of the average length of $30 \mu \mathrm{m}$, which results in $\pm 10 \%$ error in the temperature estimation of the hot end of the narrow channel.

The primary thermal conductance path is from the $\mathrm{Ti} / \mathrm{Pt}$ heater and the suspended narrow channel, where the silicon substrate is the heat-sinking thermal ground (figure 2). The relatively high power budget of the device is mainly due to the high thicknesses of the PECVD ONO-3 and $\mathrm{ALD} \mathrm{Al} \mathrm{O}_{2} \mathrm{O}_{3}$ layers in the thermal conductance path for hermetic sealing of the $\mathrm{XeF}_{2}$ access holes. In this fabrication attempt, the thicknesses are not tuned to find the minimally required thicknesses for sealing. In future generations of the Knudsen pump, higher thermal isolation could be obtained with lower thicknesses of the layers for lower thermal budget. The suspended length of the narrow channel can also be increased for additional thermal isolation.

Benchmarking illustrates a 24 times improvement in the gas compression ratio compared to the other micropumps $[1,6-8,22,35-37,43-50]$ previously reported (figure 8). The integration of 48 stages into one silicon chip, using the simple silicon-based micromachining and effective channel design, enabled substantially higher performance.

The type of pump described in this paper is intended for applications such as cavity pressure modulation and tunable vacuum control. These applications typically require the maintenance of a certain level of vacuum or a limited amount of pressure modulation; repeated pump-down from atmospheric 


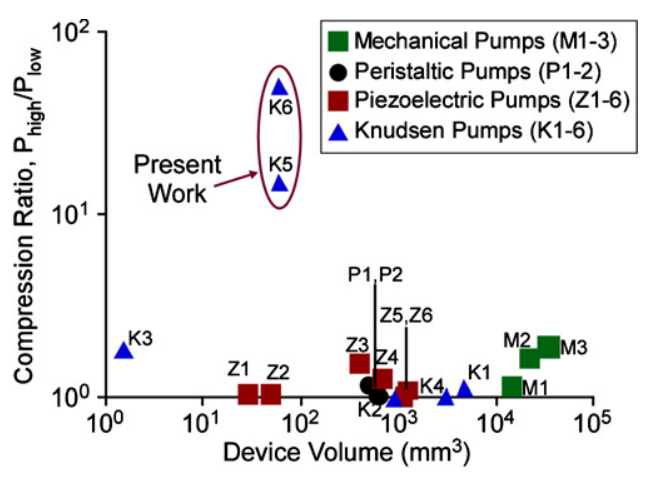

$\begin{array}{ll}\text { M1: KNF pump NMP05S } & \text { P1: Kim, 2007 } \\ \text { M2: KNF pump NMP09B } & \text { P2: Besharatian, } 2012 \\ \text { M3: KNF pump NMP015S } & \text { Z1: Wijngaart, 2000 } \\ \text { K1: Gupta, 2011 (JMM) } & \text { Z2: Gerlach, 1995 } \\ \text { K2: Gupta, 2011 (MMM) } & \text { Z3: Kamper, 1998 } \\ \text { K3: McNamara, 2005 } & \text { Z4: Bartels mp5 micropump } \\ \text { K4: Pharas, 2010 } & \text { Z5: Stemme, 1993 } \\ \text { K5: Present work } & \text { Z6: thinXXS micropumps } \\ \text { K6: Present work } & \end{array}$

Figure 8. This work has resulted in a compression ratio of 15 (if the pump is operated in 760 Torr air ambient) and a compression ratio of 50 (if it is operated in 250 Torr air ambient). A comparison to the published literature suggests that Knudsen micropumps can achieve superior compression ratios.

pressure is not anticipated. Hence, the pumping rate is not a dominant consideration. For the design implemented in this work, the total dead volume of gas that must be evacuated is $1.7 \times 10^{-4} \mathrm{~cm}^{3}$, distributed over 48 stages. The theoretical mass flow rates, calculated using equation (3), at the highpressure end (760 Torr) and the low-pressure end (50 Torr) are $8.4 \times 10^{-13}$ and $1.4 \times 10^{-13} \mathrm{~kg} \mathrm{~s}^{-1}$, respectively. The increase in the mass flow rate at the low-pressure end compared to that at the high-pressure end improves the overall pumping rate. Broadening the narrow channel for the low-pressure stages can increase the mass flow rate without compromising the compression ratio per stage, because the mean free path of gas molecules increases as the pressure decreases.

\section{Conclusion}

A five-mask process is described to fabricate a single-wafer Knudsen pump structure with 24 times better gas compression capability than other micropumps reported in the literature. This single-wafer structure is instrumental in mitigating yield problems. This effort demonstrates the feasibility of the Knudsen pump with monolithically integrated Pirani gauges for high-vacuum pumping applications. The calibration of Pirani gauges is used to measure pressures from 760 to 1 Torr pressure levels. The 48-stage Knudsen pump with monolithically integrated Pirani gauges has a footprint of $10.35 \times 11.45 \mathrm{~mm}^{2}$. For an input power of $1350 \mathrm{~mW}$, it pumps down from 760 to $\approx 50$ Torr and from 250 to $\approx 5$ Torr with ambient air as the operating medium. The study suggests that the thickness of the ONO-3 and the ALD $\mathrm{Al}_{2} \mathrm{O}_{3}$ layers could be reduced to limit the power budget of the device without affecting its performance in the compression ratio.

\section{Acknowledgments}

The authors thank Mr Venkat Dukkipati for his valuable input on possible methods to seal the pinholes in PECVD oxide and nitride layers, and Mr Yutao Qin for the FEA simulation of the diaphragm deflection with varying structural supports. SA acknowledges partial support by a fellowship from the Electrical Engineering and Computer Science at the University of Michigan. The study is supported in part by the Microsystems Technology Office of the Defense Advanced Research Projects Agency High-Vacuum Program (DARPA Hi-Vac). Facilities used for this research include the Lurie Nanofabrication Facility (LNF) operated by the SolidState Electronics Laboratory (SSEL) and the University of Michigan.

\section{References}

[1] Stemme E and Stemme G 1993 A valveless diffuser/nozzle-based fluid pump Sensors Actuators A 39 159-67

[2] Schomburg W K, Vollmer J, Bustgens B, Fahrenberg J, Hein H and Menz W 1994 Microfluidic components in LIGA technique J. Micromech. Microeng. 4 186-91

[3] Dario P, Croce N, Carrozza M C and Varallo G 1996 A fluid handling systemfor a chemical microanalyzer J. Micromech. Microeng. 6 95-98

[4] Cabuz C, Herb W R, Cabuz E I and Son T L 2001 The dual diaphragm pump Proc. 14th IEEE Int. Conf. on Micro Electro Mechanical Systems (MEMS'O1) pp 519-22

[5] Schabmueller C G J, Koch M, Mokhtari M E, Evans A G R, Brunnschweiler A and Sehr H 2002 Self-aligning gas/liquid micropump J. Micromech. Microeng. 12 420-4

[6] Nguyen N-T, Huang X and Chuan T K 2002 MEMS-micropumps: a review Trans. ASME, J. Fluids Eng. 124 384-92

[7] Laser D J and Santiago J G 2004 A review of micropumps J. Micromech. Microeng. 14 R35-R64

[8] Kim H, Astle A A, Najafi K, Bernal L P and Washabaugh P D 2007 A fully integrated high-efficiency peristaltic 18-stage gas micropump with active microvalves Proc. 20th IEEE Int. Conf. on Micro Electro Mechanical Systems (MEMS'07) pp 127-30

[9] Tsai N-C and Sue C-Y 2007 Review of MEMS based drug delivery and dosing systems Sensors Actuators A $134555-64$

[10] Kim H T, Park J W and Kim H 2011 All-electric peristaltic vacuum pump utilizing electromagnetic and hydraulic actuation with a highly flexible latex membrane Proc. 16th Int. Conf. on Solid-State Sensors, Actuators and Microsystems (Transducers'11) pp 2454-7

[11] Knudsen M 1909 Eine revision der Gleichgewichtsbedingung der gase. Thermische Molekularstromung Ann. Phys., Lpz. 336 205-29 (in German)

[12] Liu J, Gupta N K, Fan X, Wise K D and Gianchandani Y B 2011 A pressure programmable gas chromatography microsystem utilizing motionless Knudsen pump, fiber-integrated optical detector, and silicon micromachined separation column Int. Conf. on Solid State Sensors and Actuators (Transducers'11) pp 803-6

[13] Reynolds O 1879 On certain dimensional properties of matter in the gaseous state Phil. Trans. R. Soc. $170727-845$

[14] Maxwell J C 1879 On stresses in rarefied gases arising from inequalities of temperature Phil. Trans. R. Soc. 170 231-56 
[15] Loeb L 1934 The Kinetic Theory of Gases (New York: McGraw Hill) pp 355-9

[16] Kennard E 1938 The Kinetic Theory of Gases (New York: McGraw Hill) pp 327-32

[17] Karniadakis G E, Beskok A and Aluru N 2005 Microflows and Nanoflows: Fundamentals and Simulation (New York: Springer) chapter 1

[18] Rojas Cardenas M, Graur I, Perrier P and Meolans J G 2011 Thermal transpiration flow: a circular cross-section microtube submitted to a temperature gradient Phys. Fluids 23031702

[19] Vargo S E and Muntz E P 1996 A simple micromechanical compressor and vacuum pump for flow control and other distributed applications 34th Aerospace Sciences Meeting and Exhibit (Reno, NV, January 1996)

[20] Vargo S E and Muntz E P 2001 Initial results from the first MEMS fabricated thermal transpiration-driven vacuum pump AIP Conf. Proc. no $\mathbf{5 8 5}$ pp 502-9

[21] Muntz E P, Sone Y, Aoki K, Vargo S and Young M 2002 Performance analysis and optimization considerations for a Knudsen compressor in transitional flow J. Vac. Sci. Technol. A 20 214-24

[22] McNamara S and Gianchandani Y B 2005 On-chip vacuum generated by a micromachined Knudsen pump J. Microelectromech. Syst. 14 741-6

[23] Colin S 2005 Rarefaction and compressibility effects on steady and transient gas flows in microchannels Microfluid Nanofluid $1268-79$

[24] Alexeenko A A, Gimelshein S F, Muntz E P and Ketsdever A D 2005 Modeling of thermal transpiration flows for Knudsen compressor optimization 43rd AIAA Aerospace Sciences Meeting and Exhibit-Meeting Papers pp 9419-29

[25] Alexeenko A A, Gimelshein S F, Muntz E P and Ketsdever A D 2006 Kinetic modeling of temperature driven flows in short microchannels Int. J. Therm. Sci. 45 1045-51

[26] Gupta N K, Masters N D, Ye W and Gianchandani Y B 2007 Gas flow in nano-channels: thermal transpiration models with application to a Si-micromachined Knudsen pump Proc. 14th Int. Conf. on Solid-State Sensors, Actuators and Microsystems (Transducers'07) pp 2329-32

[27] Kosuge S and Takata S 2008 Database for flows of binary gas mixtures through a plane microchannel Eur. J. Mech. B 27 444-65

[28] Young M, Han Y L, Muntz E P and Shiflett G 2005 Characterization and optimization of a radiantly driven multi-stage Knudsen compressor AIP Conf. Proc. 762 174-9

[29] Han Y-L and Muntz E P 2007 Experimental investigation of micro-mesoscale Knudsen compressor performance at low pressures J. Vac. Sci. Technol. B 25 703-14

[30] Han Y-L and Muntz E P 2008 Investigation of temperature driven gas flow in $4 \mathrm{~nm}$ channels for applications of micro-scale compressors at above atmospheric pressure Proc. ASME Int. Mechanical Engineering Congress and Exposition, vol 3 661-8

[31] Gupta N K and Gianchandani Y B 2008 Thermal transpiration in zeolites: a mechanism for motionless gas pumps Appl. Phys. Lett. 93193511
[32] Guo X, Singh D, Murthy J and Alexeenko A A 2009 Numerical simulation of gas-phonon coupling in thermal transpiration flows Phys. Rev. E 80046310

[33] Gupta N K and Gianchandani Y B 2009 A planar cascading architecture for a ceramic Knudsen micropump Proc. 15th Int. Conf. on Solid-State Sensors, Actuators and Microsystems (Transducers'09) pp 2298-301

[34] Gupta N K 2010 A motionless gas micropump using thermal transpiration in bulk nanoporous materials $P h D$ Dissertation University of Michigan

[35] Pharas K and McNamara S 2010 Knudsen pump driven by a thermoelectric material J. Micromech. Microeng. 20125032

[36] Gupta N K and Gianchandani Y B 2011 Thermal transpiration in mixed cellulose ester membranes: enabling miniature, motionless gas pumps Microporous Mesoporous Mater. 142 pp 535-41

[37] Gupta N K and Gianchandani Y B 2011 Porous ceramics for multistage Knudsen micropumps-modeling approach and experimental evaluation J. Micromech. Microeng. 21095029

[38] Young M, Han Y L, Muntz E P, Shiflett G, Ketsdever A and Green A 2003 Thermal transpiration in microsphere membranes 23rd Int. Symp. on Rarefied Gas Dynamics vol 663 pp 743-51

[39] Gupta N K, An S and Gianchandani Y B 2012 A monolithic 48-stage Si-micromachined Knudsen pump for high compression ratios Proc. 25th IEEE Int. Conf. on Micro Electro Mechanical Systems (MEMS'12) pp 152-5

[40] Sharipov F and Seleznev V 1998 Data on internal rarefied gas flows J. Phys. Chem. Ref. Data 27 657-706

[41] Sharipov F 1999 Non-isothermal gas flow through rectangular microchannels J. Micromech. Microeng. 9 394-401

[42] Doms M, Bekesch A and Mueller J 2011 A microfabricated Pirani pressure sensor operating near atmospheric pressure J. Micromech. Microeng. 15 1504-10

[43] Gerlach T and Wurmus H 1995 Working principle and performance of the dynamic micropump Sensors Actuators A 50 135-40

[44] Kamper K P, Dopper J, Ehrfeld W and Oberbeck S 1998 A self-filling low-cost membrane micropump Proc. 11th IEEE Int. Conf. on Micro Electro Mechanical Systems (MEMS'98) pp 432-7

[45] Wijngaart W, Andersson H and Enoksson P 2000 The first self-priming and bi-directional valve-less diffuser micropump for both liquid and gas Proc. 13th IEEE Int. Conf. on Micro Electro Mechanical Systems (MEMS'00) pp 674-9

[46] Kim H, Najafi K and Bernal L 2008 Gas micropumps Comprehensive Microsystems vol 2 ed Y Gianchandani, O Tabata and H Zappe (Amsterdam: Elsevier) pp 273-300

[47] Besharatian A, Kumar K, Peterson R L, Bernal L P and Najafi K 2012 A scalable, modular, multi-stage, peristaltic, electrostatic gas micro-pump Proc. 25th IEEE Int. Conf. on Micro Electro Mechanical Systems (MEMS'12) pp 1001-4

[48] KNF website: http://www.knf.com/pdfs/nmp05_09_015.pdf

[49] Bartels website: http://www.bartels-mikrotechnik.de/ index.php/mp5.html

[50] thinXXS website: http://www.thinxxs.com/ 